\title{
A global climatological perspective on the importance of Rossby wave breaking and intense moisture transport for extreme precipitation events
}

\author{
Andries Jan de Vries \\ Correspondence to: Andries Jan de Vries (andries.devries@env.ethz.ch)
}

The copyright of individual parts of the supplement might differ from the CC BY 4.0 License. 


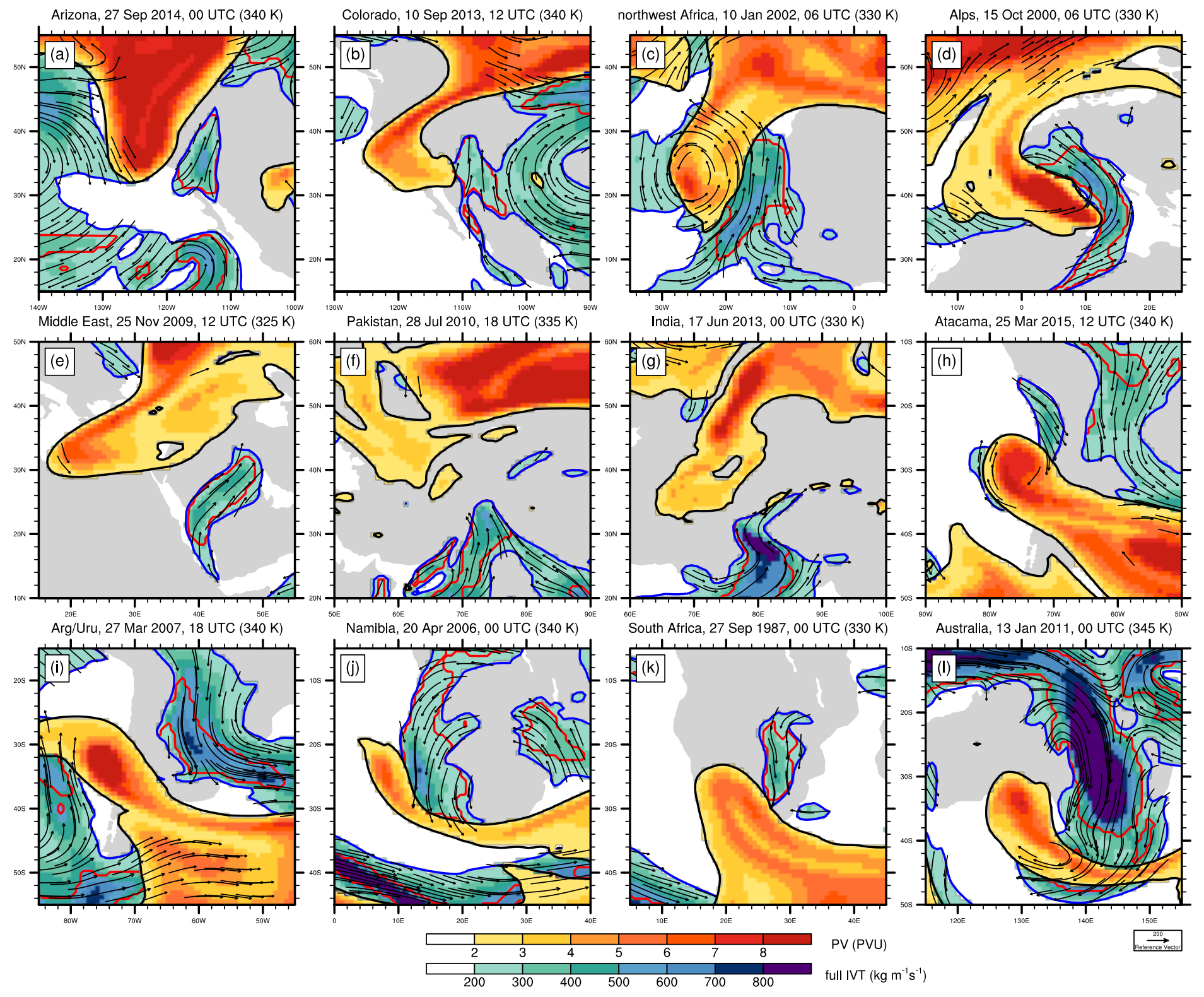

Figure S1. As Fig. 4, but with the PV and IVT fields, as depicted in Fig. 3a, used as input for the algorithm for PV and IVT structures. 

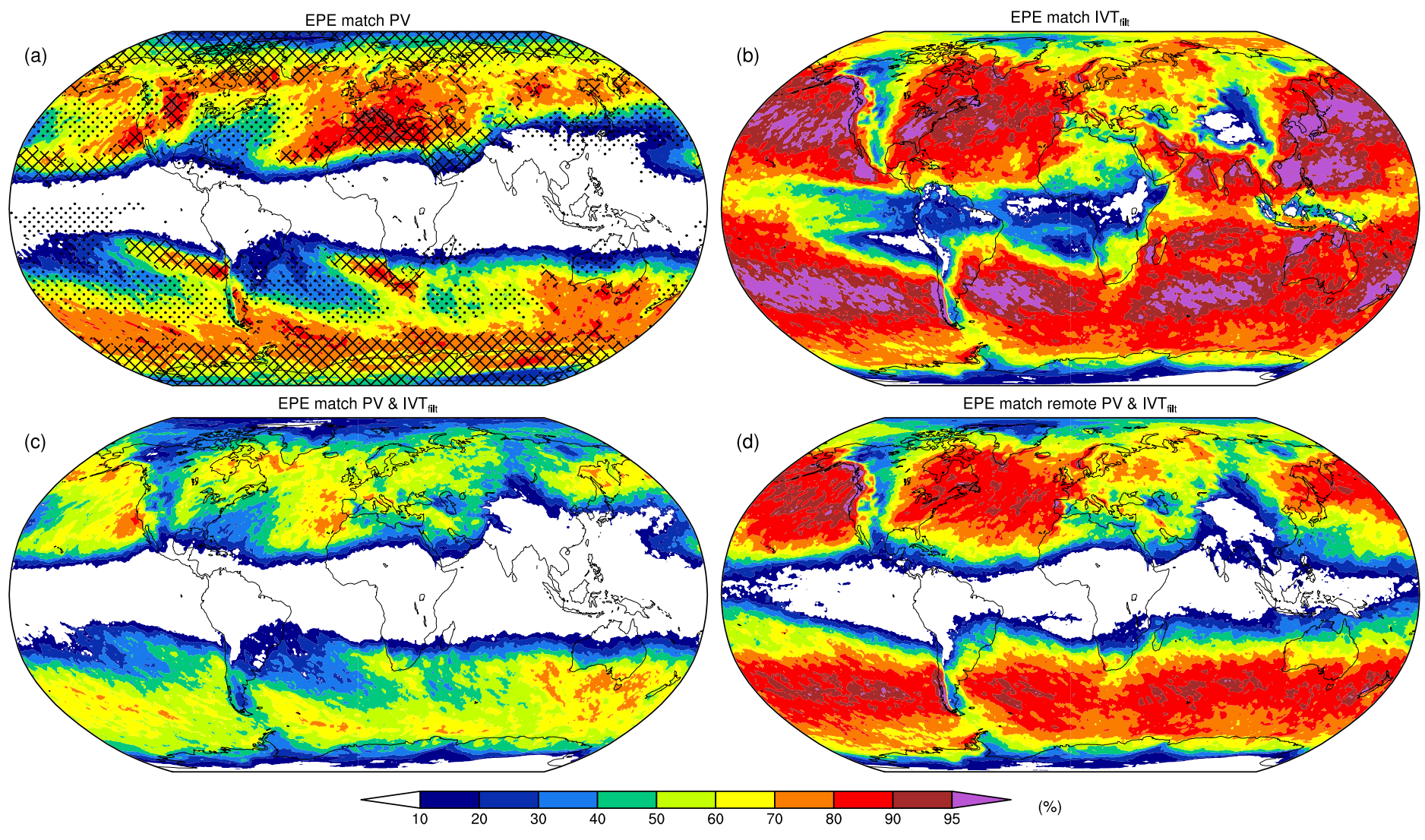

Figure S2. As Fig. 6, but for the IVTfilt form. 

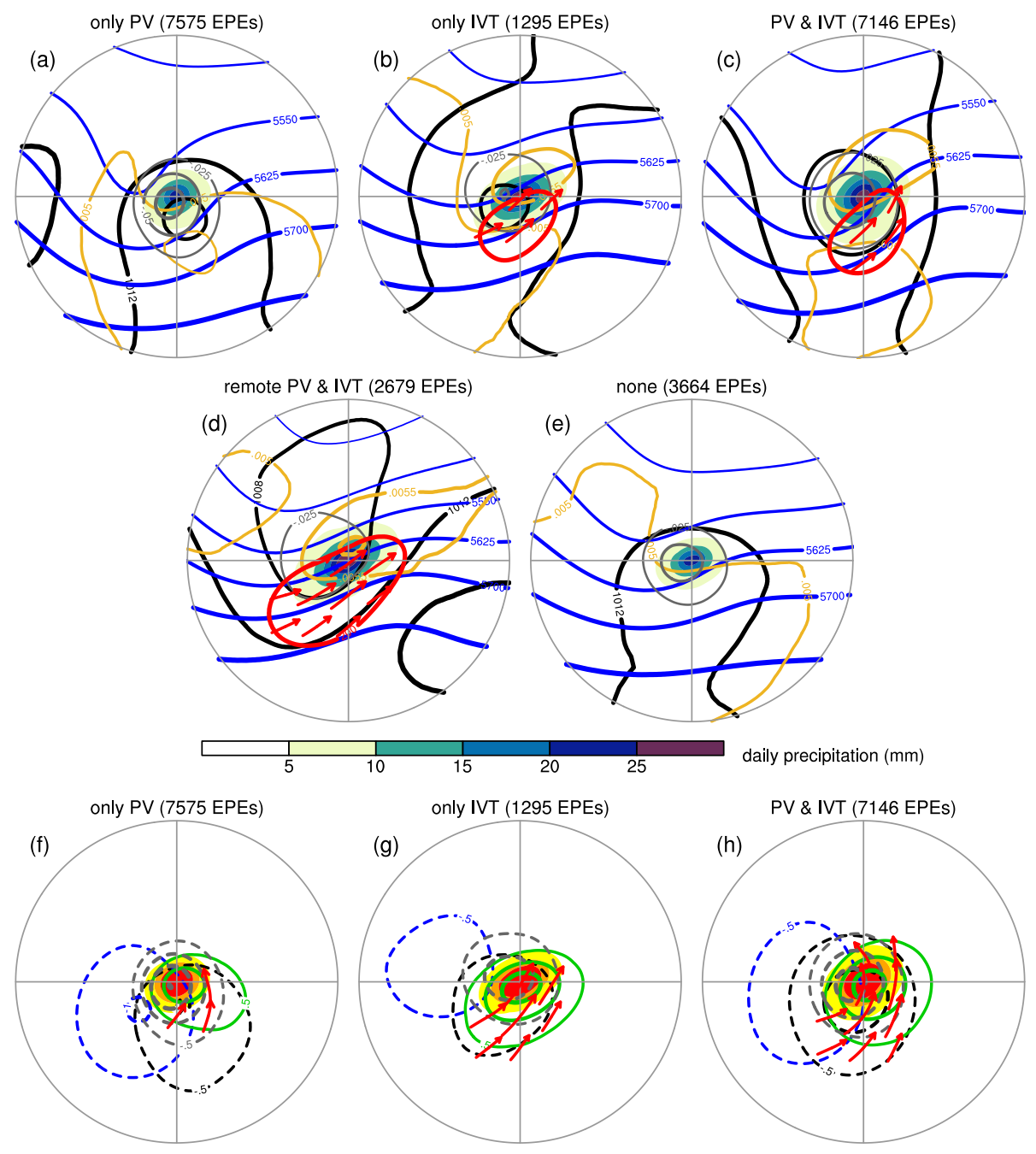

daily precipitation ( $\mathrm{mm}$ )
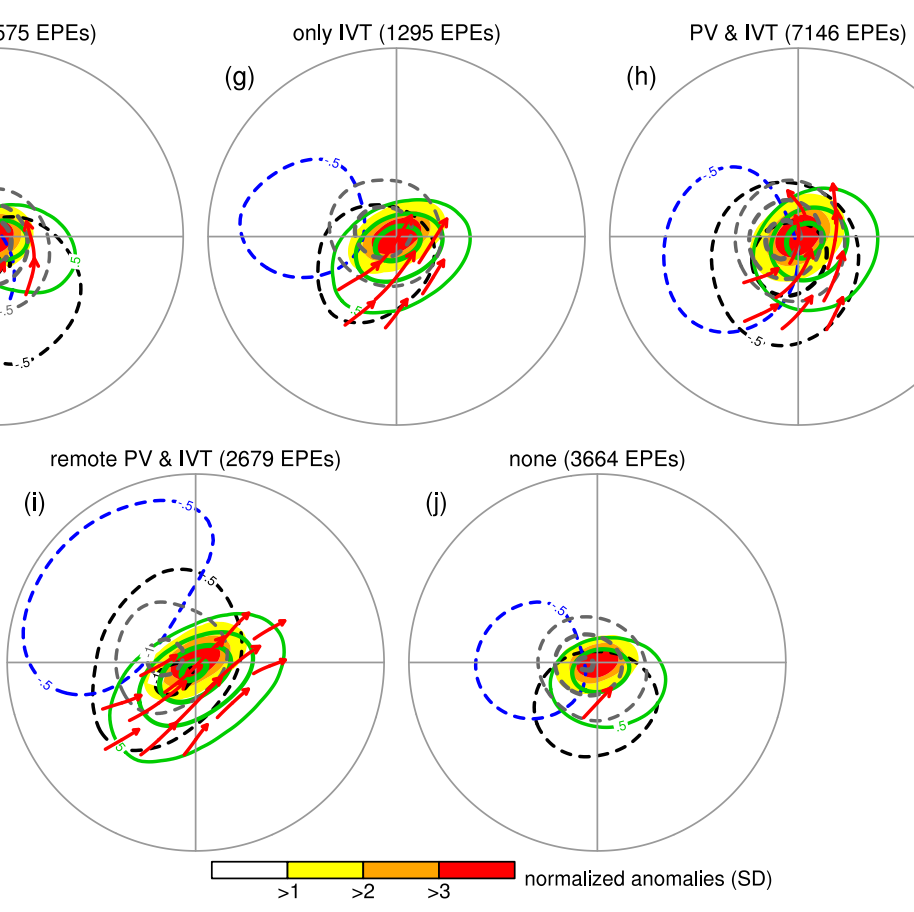

Figure S3. As Fig. 11, but for EPEs over extratropical land. 

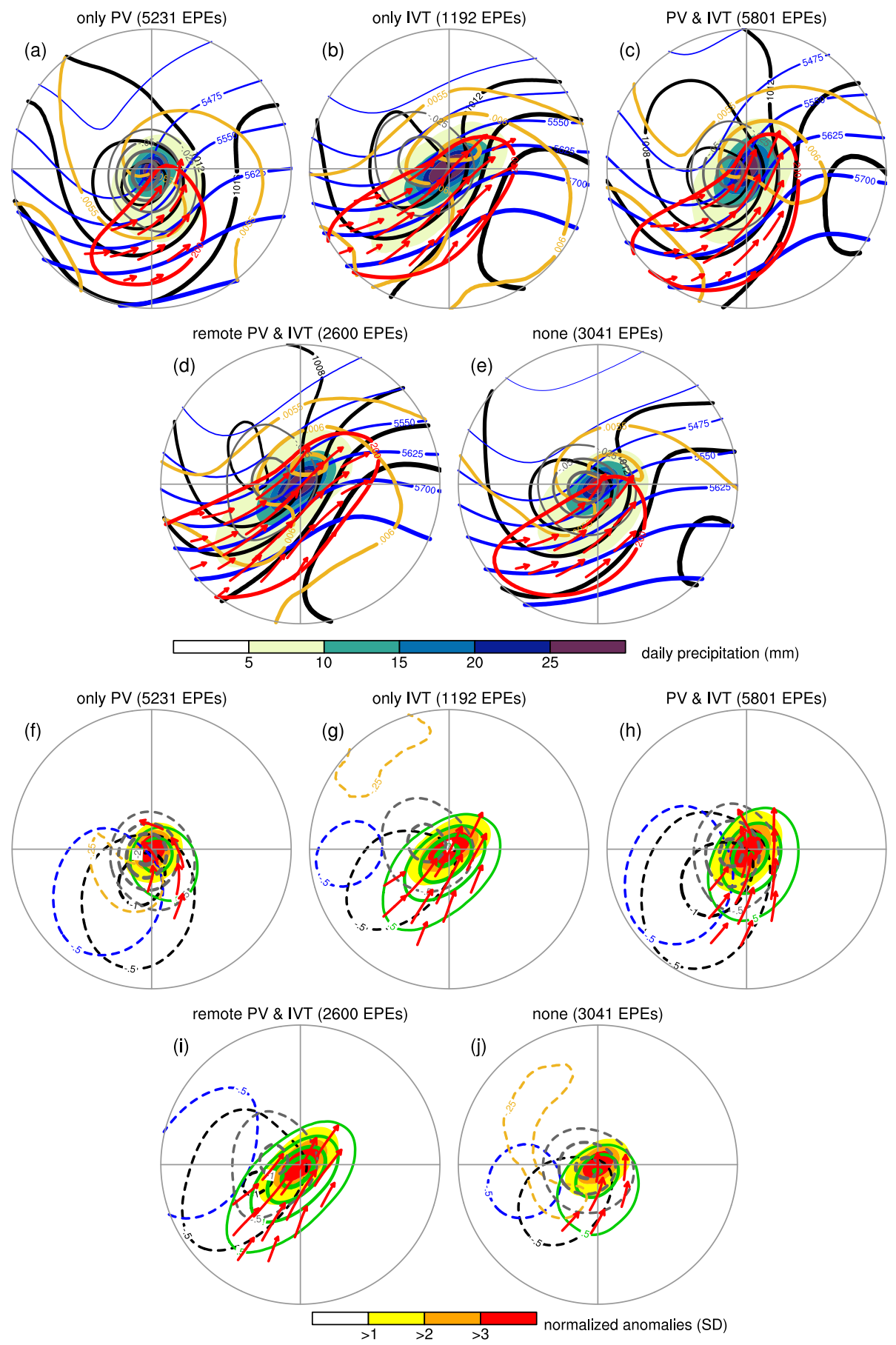

Figure S4. As Fig. 11, but for EPEs over extratropical water. 

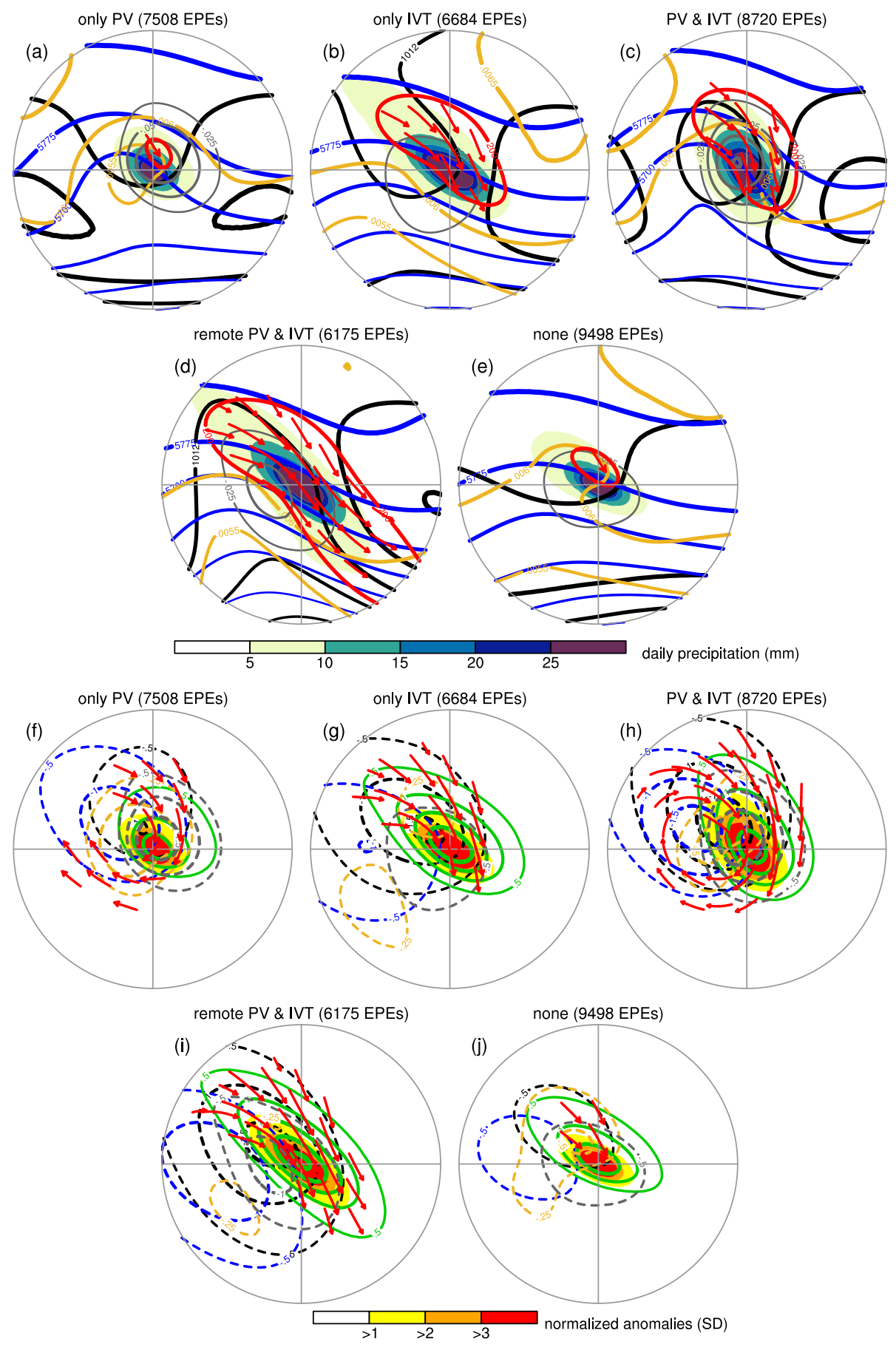

Figure S5. As Fig. 11, but for EPEs in the Southern Hemisphere over subtropical water. 

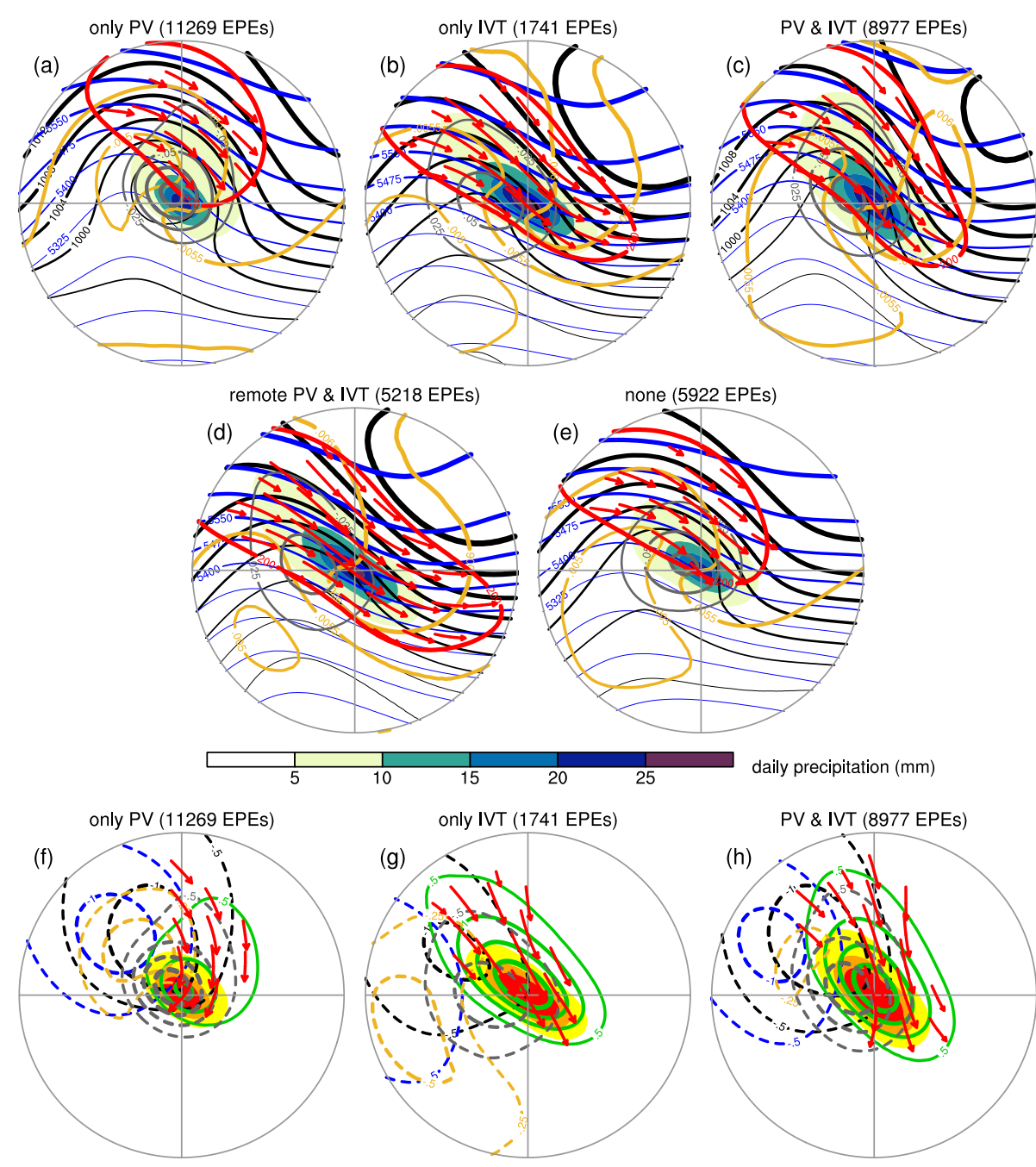

daily precipitation (mm)
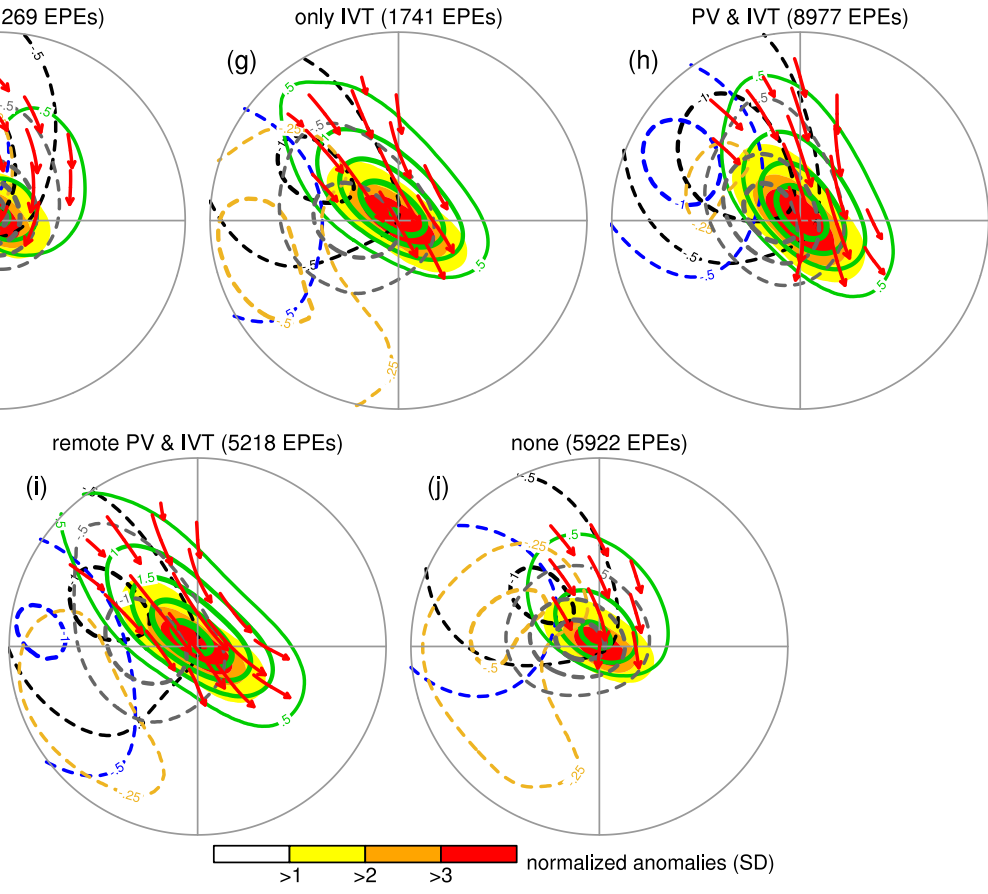

Figure S6. As Fig. 11, but for EPEs in the Southern Hemisphere over extratropical water. 

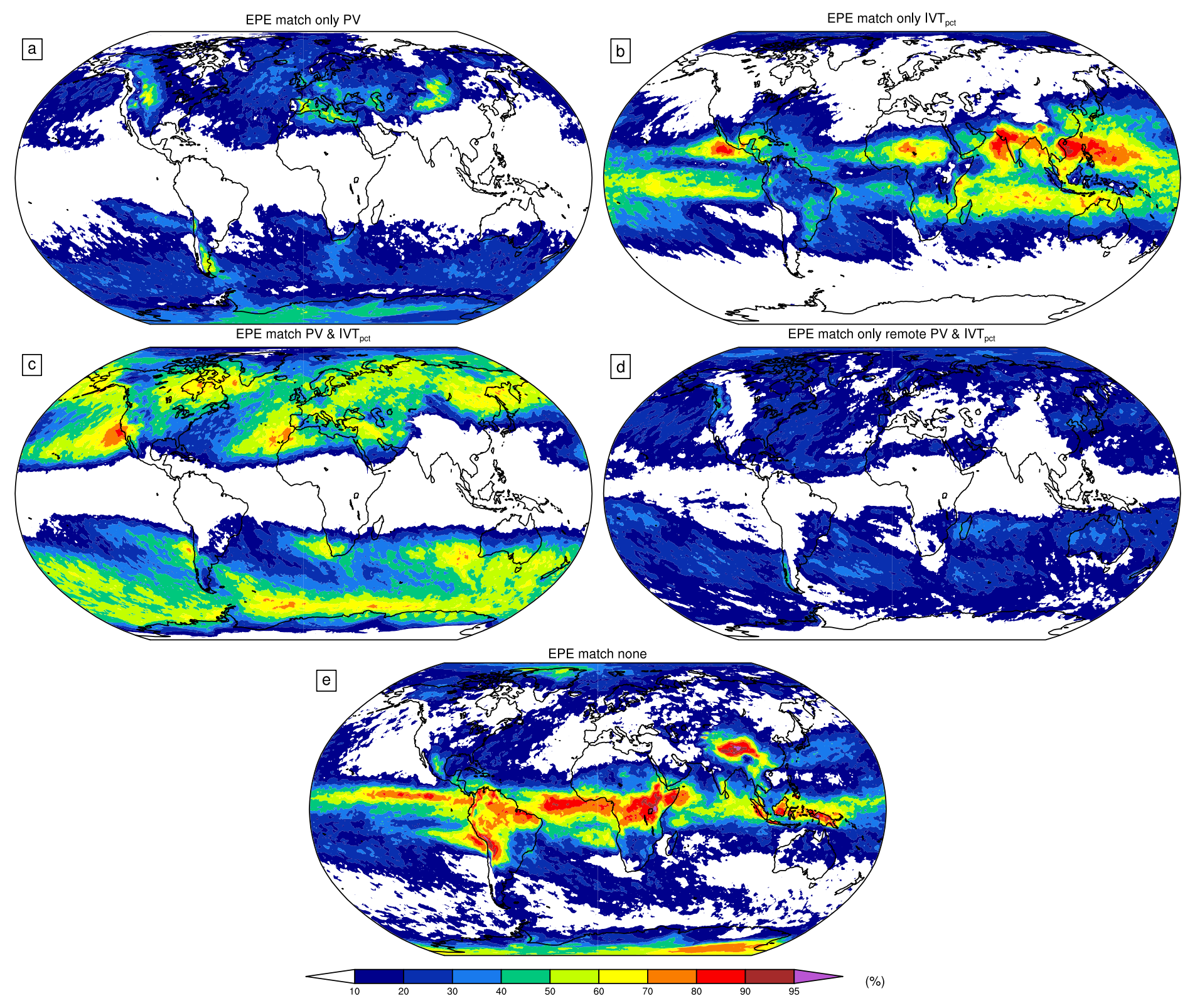

Figure S7. As Fig. 13a, but with EPE fractions in individual panels showing the full range of fractions. This Figure is analogue to Fig. 6, but with EPE fractions for the five exclusive categories. 